\title{
An assessment of remediation strategies for Kuwaiti oil lakes
}

Meshari Saad Almutairi PhD

School of Civil Engineering and Surveying, University of Portsmouth,

Portsmouth, UK (meshari.almutairi@myport.ac.uk)

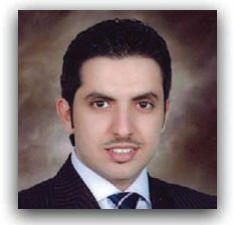

The Iraqi invasion of the state of Kuwait in 1990 inflicted one of the greatest environmental disasters, leading to a massive amount of soil becoming contaminated with oil, which has been left untreated in the deserts of Kuwait. The contaminated soil, if left untreated, has the tendency to pollute the underground watercourses as well as affect the well-being of the surrounding population. This research aims to evaluate and provide a review of the situation in relation to the oil lakes as well as understand the impact of contaminated soil on the environment of Kuwait, and therefore to find the best method of soil remediation. This work consists of two phases: the first phase summarises the results of a field survey and discusses the prospect of using different strategies for remediation of oil-contaminated soil in Kuwait, while the second phase assesses the feasibility of several soil remediation techniques in compliance with UN regulations. Soil washing was chosen to be the best alternative among ten remediation methods, based on a decision mechanism, in compliance with the House of Quality analysis system, as the results of evaluation of different methods gave the highest score of relative weight of about $18 \%$ for soil washing compared with other remediation methods.

\section{Introduction}

The state of Kuwait sustained significant and widespread environmental damage resulting from the Iraqi invasion in August 1990. During the 1991 Gulf War, the estimates were that 798 oil wells were set ablaze, 149 were damaged and 45 were gushing oil (PEC, 1999; Petroleum Economist, 1992). Several oil lakes - that is, oil accumulation in depressions - were formed. Approximately 12 billion gallons $\left(45 \cdot 4\right.$ million $\left.\mathrm{m}^{3}\right)$ of seawater, which contained a substantial amount of salt, was used to extinguish around 20-25 million barrels of ignited crude oil. The gushing oil from the oil fire plumes spread over the desert surface, covering vast areas and stretching from Kuwait to the Kingdom of Saudi Arabia. Within the vicinity of the oil wells, oil deposits were formed with various sizes of lakes and films or oil crust spreading across areas some distance away from the wells. As a result, contamination of soil and groundwater took place due to oil spray and combustion products from oil fires (Al-Awadhi et al., 1998). The spilled oil, which accumulated in low-lying areas within the Kuwait desert, created more than 300 large oil lakes. These spots, comprising a combination of water ( $28 \%$ average) and salt (in excess of $10 \%)$, oil and sand known as 'oil lakes', spread over the surface of the land. Among these lakes, 45 major lakes were in Burgan and between the Maqwa and Ahmadi oilfields. There were another 23 minor lakes (Al-Ajmi et al., 1994; El-Baz et al., 1994; Kwarteng, 1998). It is fortunate that the Kuwait Oil Company (KOC) has succeeded in recovering around 21 million barrels from the oil lakes since the end of the Gulf War. The spilled oil was recovered by pumping from the oil lakes to the oil-gathering centre and then exported as untreated oil (KOC, 2015). The oil lakes cover approximately $116 \mathrm{~km}^{2}$ (Al-Naseem and Al-Duwaisan, 2011), representing 0.65\% of the total Kuwait land area, as illustrated in Table 1. This huge scale of contamination has created environmental issues to the groundwater, air and coast. Also, the depths of these oil lakes vary from a few centimetres to a few metres, which constitutes more than 60 million barrels of crude oil. Altogether, around 660 million barrels of crude oil were released to the environment, and as a result, approximately $55 \mathrm{Mt}$ of contaminated soil remained in the lake beds. The existence of such a phenomenal amount of oil over a substantial land area represents a major environmental concern. No other petroleum catastrophe in history is as extensive as this one in Kuwait (Al-Ajmi et al., 1994; El-Baz et al., 1994; Kwarteng, 1998). As time passed, a low number of benzene ring structures of polycyclic aromatic hydrocarbons (PAHs) have evaporated on exposure to high temperature. The fine soot particles in the form of oil mist became hard, while smaller and shallower oil lakes became dry, thus forming tar mats. The fine soot particles that formed when the oil wells were burning changed the soil beneath to black. Under extreme weather conditions, these contaminants continued to disintegrate slowly. The thickness of the tar mats varies from a few millimetres to approximately $2 \mathrm{~cm}$. Based on research by Kwarteng (1998), a number of these oil lakes were covered with a veneer of sand and therefore could not be detected from the surface. In addition, at certain places, the oil travelled to new sites owing to the occasional heavy rain showers. There have not been any large-scale 
Table 1. Volume of oil trenches and oil lakes in Kuwait

\begin{tabular}{|c|c|c|c|}
\hline Source of contamination & Average depth: $\mathrm{cm}$ & Extent: $\mathbf{k m}^{2}$ & Volume: $\times 10^{6} \mathrm{~m}^{3}$ \\
\hline Dry oil lakes & 25 & $98 \cdot 38$ & $25 \cdot 5$ \\
\hline Wet oil lakes & 64 & $7 \cdot 19$ & $4 \cdot 6$ \\
\hline Oil-contaminated piles & 173 & 8.59 & $14 \cdot 8$ \\
\hline Oil trenches and pipeline spills & 351 & 1.63 & $5 \cdot 7$ \\
\hline Total & & $115 \cdot 79$ & $49 \cdot 6$ \\
\hline
\end{tabular}

Source: Al-Naseem and Al-Duwaisan (2011)

methods implemented to remediate the affected areas thus far. As such, the environment is exposed to these untreated oil lakes and contaminated surfaces. Subsequently, the government of Kuwait filed claims with the UN Compensation Commission (UNCC) seeking compensation to remediate and rehabilitate the areas that sustained environmental damage throughout the country.

In 1991, the UNCC decided to sell Iraqi oil to distribute the money as compensation for damages suffered during the invasion. In 2003, Kuwait was awarded US\$3 billion from the UNCC for environmental rehabilitation (UNCC, 2004). The rehabilitation task will be a combined effort among the KOC, the UNCC and the Kuwait National Focal Point (KNFP). KOC is scheduled to start bidding for contracts worth hundreds of millions of dollars in the forthcoming months, and this is expected to continue thereafter every year. In fact, Kuwait is the first country that has claimed compensation to rehabilitate the environment following an environmental disaster through the UN. According to experts, the entire process is expected to take approximately 25 years.

Research studies on remediation of this particular case are very rare, so the present study is very important to find an effective technique to overcome this environmental issue. This study aimed to assess the level of contamination in the affected area of the Kuwaiti desert by conducting a field survey and to find the most suitable remediation option by using House of Quality (HOQ), which is a standard comparison tool used for the evaluation of available remediation options. Similar studies employing the HOQ system in this research area were conducted by Ejbarah et al. (2011); they reported that the HOQ was used to investigate and assess the best remediation techniques for the Kuwaiti oil lake, such as soil flushing, in situ steam injection, ex situ land farming and in situ land farming. Various types of multicriteria analyses such as the pairwise comparison chart, objective tree and weighted objective tree were developed to evaluate the use of the HOQ technique against the set requirements. The total weighted score of each method was calculated to assess the final decision. In this research, a total of ten more techniques were evaluated using assigned weights obtained by Ejbarah et al. (2011).

\section{Methods}

Site investigation and soil sampling

The site investigation was carried out to identify, assess and suggest the most appropriate strategy to remediate the oil, contaminated soil. The greater Al-Burgan oilfield, in the desert in south-east Kuwait, was selected for this study. Extreme care was taken in selecting an appropriate section of the site, as areas in proximity to the oilfields have been reported to contain unexploded ammunition. The sampling site is Burgan marked as $\mathrm{X}$ in Figure 1 .

About $70 \%$ of the Kuwait's operational oil wells are located in the southern oilfields, including Ahmadi, Maqwa and Burgan, which combined to become the 'Greater Burgan' oilfield. Together with the Greater Burgan oilfield, Umm Gudair, Manigish and Wafra are also located within the southern area. Oil lakes were created in nine major oilfields with varying contamination levels. Within the oilfields, a number of oil lakes of different sizes were created. The Burgan field is considered the most adversely affected by the oil spillage in 1991, as it constitutes $40 \%$ of the total contaminated volume. The estimated oil lake areas for the Greater Al-Burgan vary from $14.07 \mathrm{~km}^{2}$ (Al-Ajmi et al., 1994) to $35.45 \mathrm{~km}^{2}$ (Kwarteng, 1998), 24.14 $\mathrm{km}^{2}$ (Kwarteng, 1999) and $24 \cdot 40 \mathrm{~km}^{2}$ (Omar et al., 2006).

The soil samples from the Burgan oilfield (Figure 1) were collected from the edge of lake 105, since this site was the most adversely contaminated among all of the sites. A hand shovel was used to remove about $3 \mathrm{~cm}$ of oily sludge (Figure 2), after which oil-contaminated soil was collected to a depth of approximately $30 \mathrm{~cm}$ below the surface level of oily sludge. Subsequently, the samples were placed into plastic containers and transported to the laboratory for further analyses.

The main parameters measured were the depth of contamination, concentration of total petroleum hydrocarbons (TPH), colour of the soil and particle size of the soil (wet sieving). Four categories of oil-contaminated soil layers were identified during the site investigation - namely, liquid oil, oily soil, tar mat and soot, layered over virgin soil with no contamination (Figure 3). The bulk of the contaminated soil to be dealt with has oily soil characteristics, and in some areas, the oily soil is under liquid oil that would also need to be ameliorated.

\section{Determination of TPH}

Determination of the percentage of total recoverable petroleum hydrocarbons in the oil-contaminated sand was carried out by a modified method as described by $\mathrm{Li}$ et al. (2012). Oilcontaminated sand $(10 \mathrm{~g})$ was placed into a screw-capped bottle 


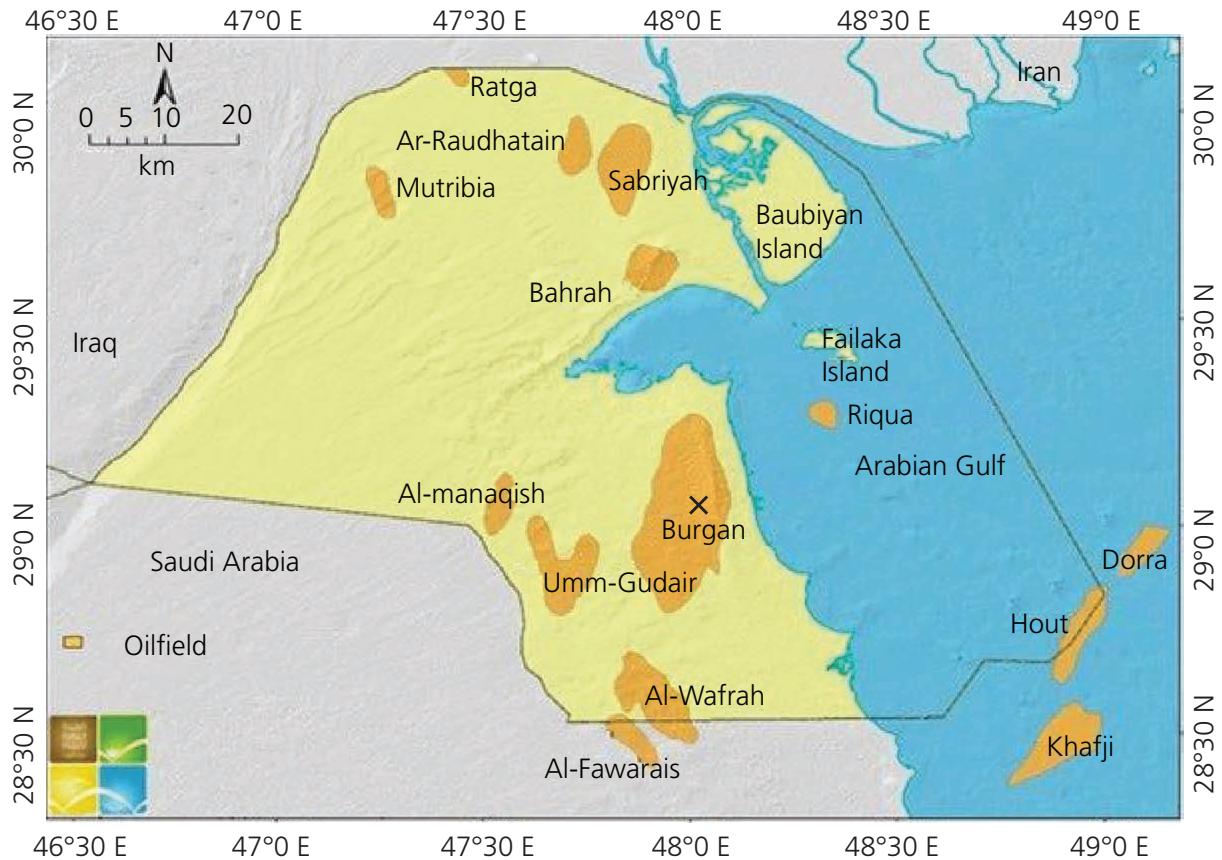

Figure 1. Map of Kuwait showing the sampling site

with $5 \mathrm{ml}$ of an acetone-hexane mixture $(1: 1 \mathrm{v} / \mathrm{v})$ and sonicated for $10 \mathrm{~min}$ in an ultrasonic water bath. The top liquid layer containing crude oil and a mixture of acetone and hexane was pipetted into a clean and dry-weighed round-bottomed flask. The ultrasonication cycle was repeated three times, and the liquid layer was collected in the same round-bottomed flask; the solvents were removed by distillation, and the weight of the dry sand was noted. Finally, after the recovery of acetone and hexane, the round-bottomed flask containing crude oil was dried and weighed to calculate the concentration of oil in the contaminated soil. The contaminated soil was subjected to washing and kept for drying; its dry weight was noted. Total petroleum hydrocarbons

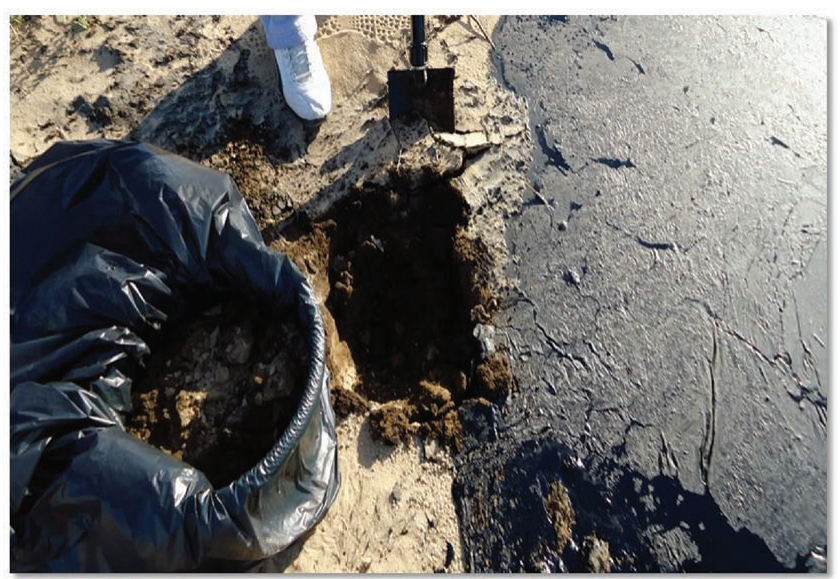

Figure 2. Sample collection
(TPH) was determined using the following equation and was expressed in milligrams per gram

$\mathrm{TPH}=\frac{\left(\begin{array}{c}\text { weight } \text { of crude oil sediment plus } \\ \text { round-bottomed flask } \\ - \text { weight of round-bottomed flask }\end{array}\right) \times 1000}{\text { weight of sample in grams }} \mathrm{mg} / \mathrm{g}$

1.

\section{Permeability test}

The constant-head test (BS 1377-5:1990, method 5 (BSI, 1990a)) was used for the measurement of permeability of the contaminated soil, which is a measure of its capacity to allow the flow of water through the pore spaces between solid particles. The degree of permeability is determined by applying a hydraulic pressure gradient in a sample of saturated soil and measuring the consequent rate of flow. The coefficient of permeability is expressed as velocity.

\section{Sieve analysis}

Based on British standards (BS 1377-2:1990 (BSI, 1990b)), mechanical sieve analysis was carried out using a sieve shaker (Retsch AS 200 sieve shaker) to determine the distribution of the grain sizes of contaminated particles. Six sieves with pore sizes of $3 \cdot 35-3 \cdot 00,2 \cdot 00,1 \cdot 60,1 \cdot 00,0 \cdot 15$ and $0 \cdot 063 \mathrm{~mm}$ and a pan were used, and the sieve analysis was performed using tap water from a nozzle spray placed on the top sieve. The contaminated sample $(1 \mathrm{~kg})$ was placed on the largest sieve at the top, and the rinsing 
An assessment of remediation strategies

for Kuwaiti oil lakes

Almutairi

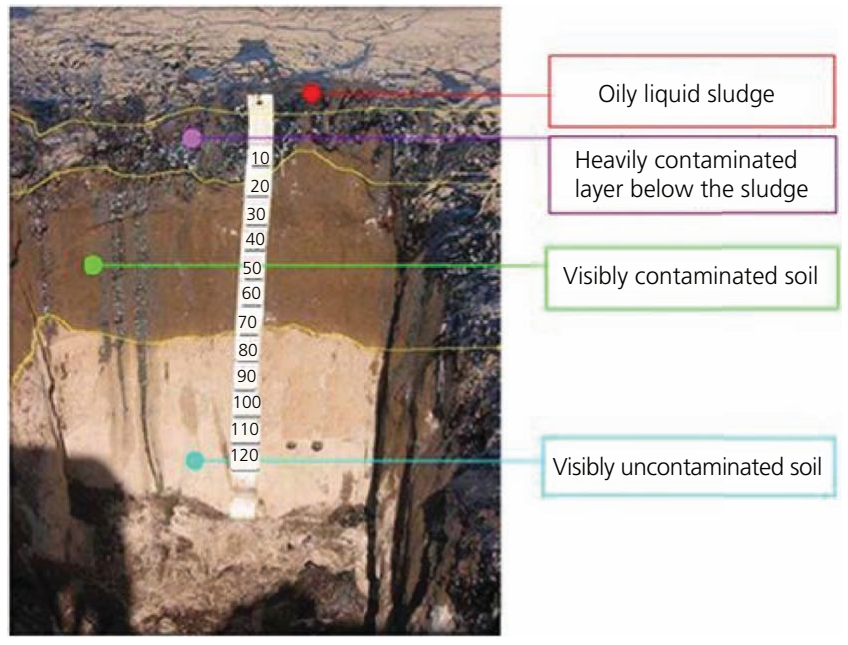

Figure 3. Layers in the oil lake at Burgan oilfield in the state of Kuwait

process continued for approximately 5 min until the sieving solutions became clear.

\section{Determination of $\mathrm{pH}$ of soil sample}

The $\mathrm{pH}$ of the oil-contaminated sand was measured according to BS ISO 10390:2005 (BSI, 2005). The oil-contaminated soil sample $(30 \mathrm{~g})$ was dried for $24 \mathrm{~h}$ in a drying cabinet at $40^{\circ} \mathrm{C}(\mathrm{Lec}$, UK), reweighed and placed into a beaker containing $150 \mathrm{ml}$ of distilled water and mixed for $10 \mathrm{~min}$ by a mechanical stirrer (Cole-Parmer). The mixture was then left to settle for $1 \mathrm{~h}$ at room temperature. The samples were then read using a $\mathrm{pH}$ meter (model, Jenway 3305, UK) after being calibrated for $\mathrm{pH} 7$.

\section{Electrical conductivity measurement}

The oil-contaminated soil was mixed with distilled water to measure the electric conductivity (in $\mu \mathrm{S} / \mathrm{cm}$ ) with a weight-tovolume ratio of 1:5. The conductivity of the oil-contaminated soil was measured using a Jenway 4010 conductivity meter (BS EN 13038: 2011 (BSI, 2011)).

\section{Determination of remediation options}

A number of options, such as a pairwise comparison chart, decision matrix, force field analysis, cost-benefit analysis and $\mathrm{HOQ}$, are available for the decision-making process in the choice of a suitable remediation method. Out of these available methods, the HOQ was selected in the present research work. HOQ is a simple decision mechanism which can be employed at various phases of product manufacturing and advertising (Figure 4). This function deployment tool can be utilised to collate customer needs and develop the product specifications as well as communicate these specifications to an enhanced procedure of manufacturing.

Upon outlining and assigning weight to each specification, the personnel responsible for decision-making ought to define the

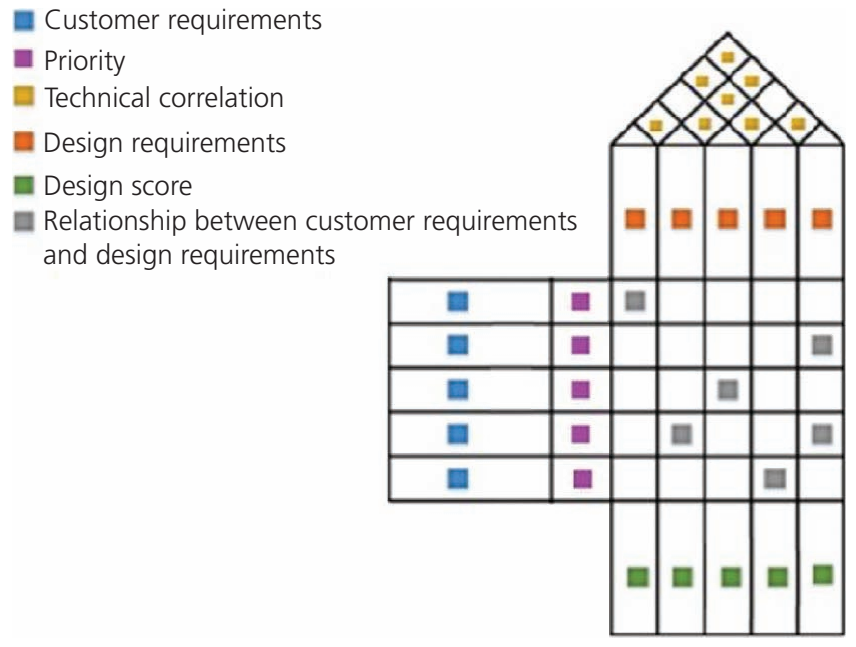

Figure 4. Overview of HOQ analysis system

weighted symbols for the processes that constitute the interlink between the proposed processes and specifications and the nonweighted symbols between the processes themselves. Towards the end, the accumulated score for each process is determined by calculating the sum of the product of the specified weight by the equivalent symbol weight (Hauser and Clausing, 1988; Russel and Taylor, 2006). Moreover, HOQ provides assistance to engineers in focusing on specified needs and deciding on the best sequence in the case that the process goes ahead. The aforementioned attributes are substantial reasons behind the choice of HOQ as the decision-making tool in this study.

\section{Establishment of HOQ}

For the purpose of selecting the most appropriate treatment method, the chemical and physical properties of the lake as well as unexploded ammunition, weathered soil and local conditions were taken into consideration. Relationships were established between preset objectives outlined by UNCC and KNFP and various methods of soil remediation.

The descriptions of the UN requirements (UNCC, 2004) for appropriate soil remediation strategy are as follows

(a) being capable of remediating severely contaminated soil

(b) being able to operate under severe weather conditions (extreme temperature)

(c) being simple to operate and assemble/dismantle parts

(d) the least side-effect on soil, air, employees, groundwater and neighbouring environment

(e) does not need longer time duration

$(f)$ in compliance with the requirements of the Environmental Protection Agency (EPA)

( $g$ ) good previous success rate in Kuwait or comparable conditions

(h) no direct use of thermal treatment. 
An assessment of remediation strategies

for Kuwaiti oil lakes

Almutairi
Table 2. Weights of engineering characteristics (Ejbarah et al., 2011)

\begin{tabular}{lc} 
Engineering characterisation & $\begin{array}{c}\text { Assigned } \\
\text { weight }\end{array}$ \\
\hline Reduction in major contaminants & 0.360 \\
Can be used in Kuwait's climatic conditions & 0.180 \\
Does not cause health problems to the worker & 0.120 \\
Simple to operate and assemble & 0.070 \\
Generates least residuals & 0.030 \\
Creates least equipment contaminants & 0.030 \\
The least pollution to air & 0.027 \\
Only a small area needed & 0.020 \\
The least pollution to groundwater & 0.018 \\
Does not cause noise pollution & 0.015 \\
Requires shorter duration & 0.010 \\
In compliance with the requirements of EPA & 0.060 \\
Previous experience in Kuwait or similar & 0.060 \\
surroundings & \\
Total score & 1 \\
\hline
\end{tabular}

In an effort to assign weights to these criteria, Ejbarah et al. (2011) carried out a series of discussions with consultants, environmental engineers and scientists and undertook an extensive literature review. Based on the outcomes of their study, weights were assigned to each objective, creating the weighted objectives (Table 2). The outcome of this study is utilised to distinguish, appraise various solutions and determine the importance of the objectives listed.

\section{Definition of the relationships between symbols and weights}

The relationships between each soil remediation method and the characteristics are evaluated in Figure 5, the main aim of which is to select the most suitable remediation method among the available alternatives.

\section{Investigation of alternative methods}

The term 'soil remediation' refers to the technology for eradicating or reducing the risks associated with contaminated soil. There are several ways of achieving this objective, and the most appropriate option is governed by various factors, such as the type of contaminants, the site conditions and financial constraints. Nathanail and Bardos (2004) described remediation as the action of removing, degrading or transforming contaminants to safe and stable substances. Ex situ and in situ remediation technologies for remediation of petroleum-contaminated soils can be categorised depending on their treatment mechanism as physical, chemical, thermal adsorption, biological and electrochemical remediation (Riser-Roberts, 1998). Ex situ soil washing was developed recently in an effort to remediate soils contaminated with petroleum (Sui and $\mathrm{Ji}, 2010$ ). Due to the huge differences in the physical, chemical and biological characteristics of the contaminants, as well as the large number of soil remediation methods available, selection of an appropriate and economical technology for the remediation of particular contaminants can be arduous. For this study, ten soil remediation techniques - land farming, windrow, phytoremediation, vermiremediation, bioventing, soil washing, biopiles, electroremediation, solidification/stabilisation and thermal adsorption were assessed using the HOQ matrix system. These approaches have been selected in accordance with previous attempts to remediate hydrocarbon-contaminated soil.

\section{Results and discussion}

Field survey

The most adversely affected area in the Burgan oilfield was chosen for sampling, because any other site would have only a lower level of contamination, which in turn will ensure the success rate of the chosen remediation mechanism. The layers of contaminated oil can be segregated based on their colour and the consistency of oil. Typically, the colour of liquid oil is black and it is non-coherent; oily soil is dark brown to black with a moderate to slightly hard consistency, while tar mat is also black in colour with a hard consistency. It was found that, in places, these oil lakes are as deep as $70 \mathrm{~cm}$ below ground, and as a result, the oil has infiltrated into soil to various depths. A thick oily sludge deposit has covered the affected areas with a thicker layer beneath, and oil has seeped through aided by gravity and rainfall (Al Ajmi et al., 1994; Kwarteng, 1998). Moreover, the quality of the oil has deteriorated due to prolonged exposure to the extreme weather. The volatile hydrocarbons within the oil structure have evaporated, and the oil has endured changes in its chemical and physical properties, which make its sale no longer lucrative. Omar et al. (2006) suggested that contaminated soils in general have three dimensions and form layers as they get deeper into the ground. The nature of the layers and the manner in which they are arranged provide an indication of the category of contamination; the three contamination categories described below are exhibited in Figures 6(a)-6(c).

Various types of soil layers contaminated with oil cannot be differentiated using only the analytical results. As such, field investigation is key in classifying these contaminations, as they possess varying characteristics and require different methods to remediate or options of land use (for example, tar mat is very consistent, whereas liquid oil has a weak consistency).

\section{Soil properties of oil lake}

Initial characterisation of the soil must be undertaken prior to the start of the experiment. This will provide a baseline for the site investigation. In this case, it is important to know the permeability of the soil to simulate the field conditions for conducting laboratory experiments. For potential projects, it is important to have a good understanding of the hydrological regime and how it can apply to moderate- to high-permeability soils as well as various types of contaminants. Soil properties can be divided into two categories: physical and chemical properties. The physical properties of the soil taken from the Burgan area were analysed according to the soil layers. A soil permeability test was conducted using a constant head test to simulate the field conditions and provide hydraulic flow for the sample. The samples were considered as rapidly permeable soil, with an average permeability rate of $0.064 \mathrm{~mm} / \mathrm{s}$. This value 


\begin{tabular}{|cc|}
\hline \multicolumn{2}{|c|}{ Score } \\
\hline 9 & Strong positive a weight of \\
3 & Positive a weight of \\
1 & Moderate a weight of \\
\hline \multicolumn{2}{|c|}{ Correlations } \\
\hline+ Methods operate in series without problems \\
- Methods operate in series with concerns \\
$*$ & Methods cannot operate in series \\
\hline \multicolumn{4}{|c}{ Relationships } \\
\hline 0 & Strong \\
$\nabla$ & Moderate \\
\hline
\end{tabular}

\begin{tabular}{|lc|}
\hline & Direction of improvement \\
\hline \multirow{\Delta}{*}{} & Maximise \\
$\nabla$ & Target \\
\hline
\end{tabular}

\begin{tabular}{|c|c|c|c|c|c|c|c|c|c|c|c|c|c|c|c|}
\hline & & & & & \multirow{2}{*}{\begin{tabular}{|l} 
Customer assessment \\
Direction of improvement
\end{tabular}} & \multicolumn{2}{|c|}{\begin{tabular}{l|l}
1 & 2 \\
\end{tabular}} & \multirow{2}{*}{3} & \multirow{2}{*}{4} & \multirow{2}{*}{$\begin{array}{l}5 \\
\diamond\end{array}$} & \multirow{2}{*}{$\begin{array}{c}6 \\
\nabla\end{array}$} & \multirow{2}{*}{$\begin{array}{r}7 \\
\Delta\end{array}$} & \multirow{2}{*}{8} & \multirow{2}{*}{$\begin{array}{r}9 \\
\boldsymbol{\Delta}\end{array}$} & \multirow{2}{*}{\begin{tabular}{|l|}
10 \\
$\mathbf{A}$
\end{tabular}} \\
\hline & & & & & & $\boldsymbol{\Delta}$ & $\Delta$ & & & & & & & & \\
\hline$\sum_{0}^{3}$ & 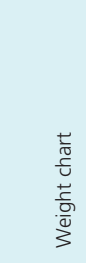 & 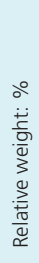 & 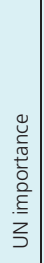 & 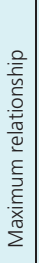 & $\begin{array}{l}\text { UN } \\
\text { requirements } \\
\text { (explicit and } \\
\text { implicit) }\end{array}$ & 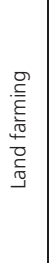 & $\begin{array}{l}\frac{3}{0} \\
\frac{0}{0} \\
\frac{c}{5} \\
3\end{array}$ & $\frac{\tilde{\tilde{U}}}{\frac{\overline{0}}{\tilde{0}}}$ & 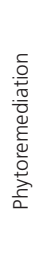 & 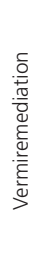 & 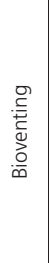 & 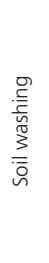 & 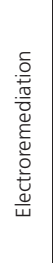 & 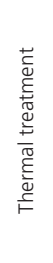 & 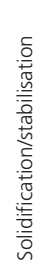 \\
\hline 1 & 1 & 3 & 1 & 9 & Short treatment time & $\nabla$ & $\bigcirc$ & $\nabla$ & $\nabla$ & $\bigcirc$ & $\bigcirc$ & 0 & 0 & 0 & 0 \\
\hline 2 & || & 7 & 7 & 9 & Easy to operate & 0 & 0 & 0 & 0 & 0 & 0 & 0 & $\nabla$ & $\nabla$ & 0 \\
\hline 3 & I & 2 & 2 & 9 & Requires small area & $\nabla$ & $\nabla$ & 0 & 0 & 0 & 0 & 0 & 0 & 0 & 0 \\
\hline 4 & $\|$ & 6 & 6 & 9 & Experience in Kuwait & 0 & 0 & 0 & 0 & $\nabla$ & $\nabla$ & 0 & $\nabla$ & $\nabla$ & $\nabla$ \\
\hline 5 & |inina & 18 & 2 & 9 & Applicable to Kuwait's weather & $\nabla$ & $\nabla$ & $\nabla$ & $\nabla$ & $\nabla$ & 0 & 0 & 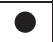 & 0 & 0 \\
\hline 6 & 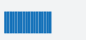 & 36 & 36 & 9 & Reduces high contaminants & O & $\bigcirc$ & $\bigcirc$ & $\bigcirc$ & $\bigcirc$ & 0 & 0 & O & 0 & \\
\hline 7 & | & 3 & 3 & 9 & Minimum residuals & 0 & 0 & 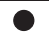 & 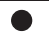 & 0 & 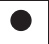 & $\nabla$ & $\mathrm{O}$ & 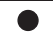 & 0 \\
\hline 8 & | & 2 & 2 & 9 & Minimum groundwater pollution & $\nabla$ & $\nabla$ & $\nabla$ & $\nabla$ & $\nabla$ & 0 & 0 & $\nabla$ & 0 & 0 \\
\hline 9 & & 1 & 1 & 9 & Minimum air pollution & $\nabla$ & $\nabla$ & $\nabla$ & $\nabla$ & 0 & $\nabla$ & 0 & $\nabla$ & $\nabla$ & O \\
\hline 10 & | & 2 & 2 & 3 & Does not cause noise pollution & 0 & 0 & 0 & $\bigcirc$ & $\bigcirc$ & $\bigcirc$ & $\nabla$ & 0 & $\nabla$ & O \\
\hline 11 & || & 6 & 6 & 3 & UN and EPA requirements & 0 & 0 & 0 & O & O & 0 & 0 & 0 & $\nabla$ & $\nabla$ \\
\hline 12 & |lin| & 12 & 12 & 9 & $\begin{array}{l}\text { Does not cause human } \\
\text { health effect }\end{array}$ & 0 & 0 & 0 & 0 & 0 & 0 & 0 & 0 & $\nabla$ & 0 \\
\hline 13 & | & 3 & 3 & 9 & $\begin{array}{c}\text { Minimum equipment } \\
\text { contaminants }\end{array}$ & O & 0 & 0 & O & 0 & 0 & $\mathrm{O}$ & 0 & $\mathrm{O}$ & $\mathrm{O}$ \\
\hline & & & & & Technical importance rating & 294 & 296 & 298 & 304 & 297 & 508 & 748 & 360 & 592 & 391 \\
\hline & & & & & Relative weight: \% & 8 & 8 & 7 & 8 & 8 & 12 & 18 & 9 & 14 & 9 \\
\hline
\end{tabular}

Figure 5. Interrelationship matrix for several soil remediation methods represents a typical sandy soil (Bodó and Jones, 2013). Furthermore, mechanical sieve analysis (Figure 7) was carried out based on British standards (BSI, 1990b) for the wet sample to eliminate the coarse fraction as well as to ensure homogeneity for the oil-contaminated soil.

The chemical properties of the soil were investigated by determining the TPH of Kuwaiti oil-contaminated sand (Table 3).

The average electrical conductivity of the contaminated soil sample was found to be $2455 \mu \mathrm{S} / \mathrm{cm}$, which could be due to the presence of salts from the seawater used to extinguish fires on oil wells. Moreover, the $\mathrm{pH}$ of the contaminated sample was found to be slightly higher than the permissible level.

For the purpose of selecting the most appropriate treatment method, the chemical and physical properties of the lake, as well as the pressence of unexploded ammunition, weathered soil and local conditions were taken into consideration.

\section{Evaluating alternatives}

Several methods are now available to remediate hazardous contaminated soils, most of which are either expensive or not able to remove the contamination entirely. According to $\mathrm{Li}$ et al. 
An assessment of remediation strategies

for Kuwaiti oil lakes

Almutairi

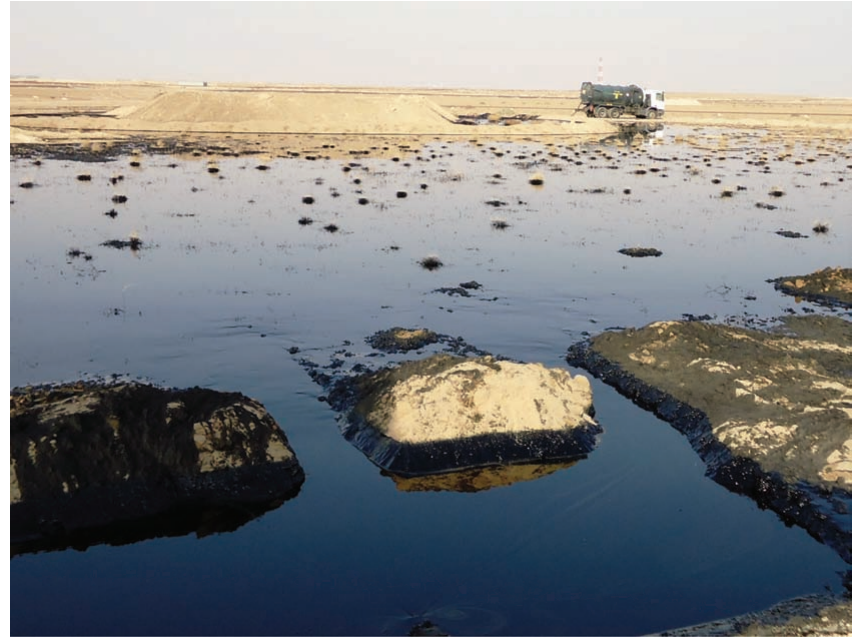

(a)

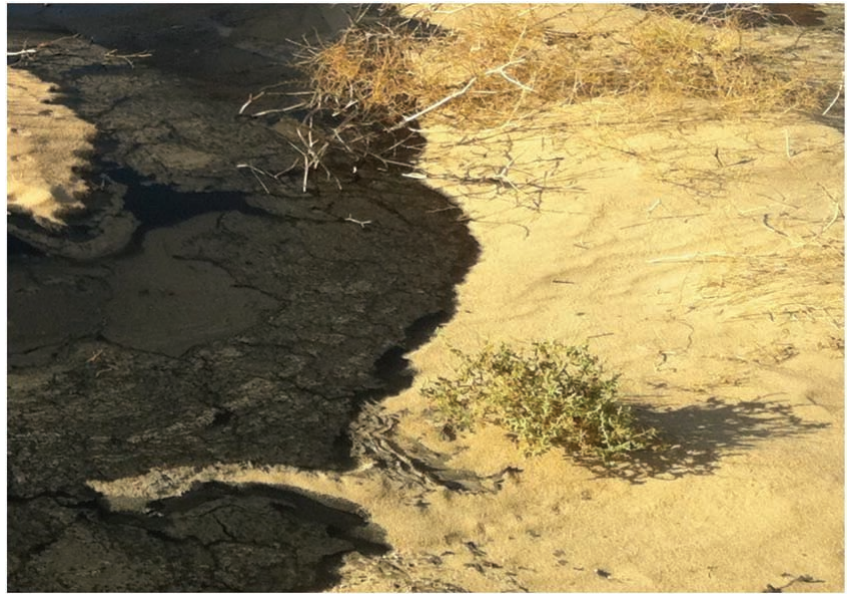

(b)

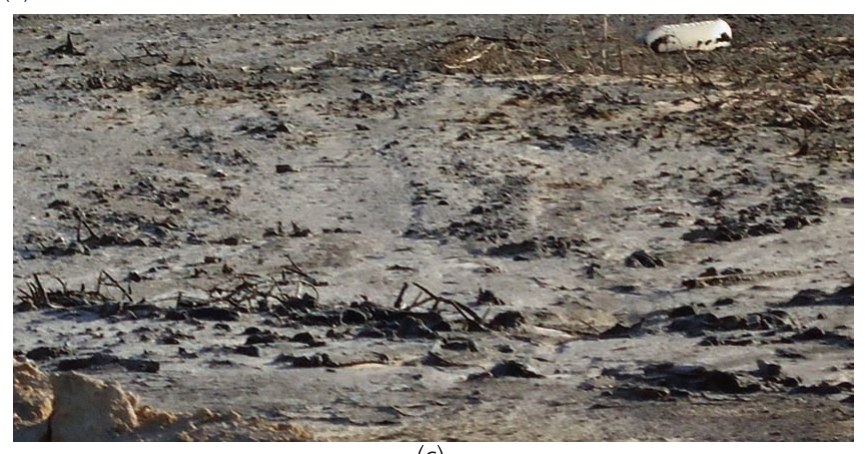

(c)

Figure 6. (a) A wet oil lake contains oil residual over the soil and has a black colour and the odour and consistency of a liquid. (b) The dry oil lake category is a tar layer over the soil that has a black colour and the consistency of semi-liquid. (c) Tar layer over the clean sand that has a hard consistency

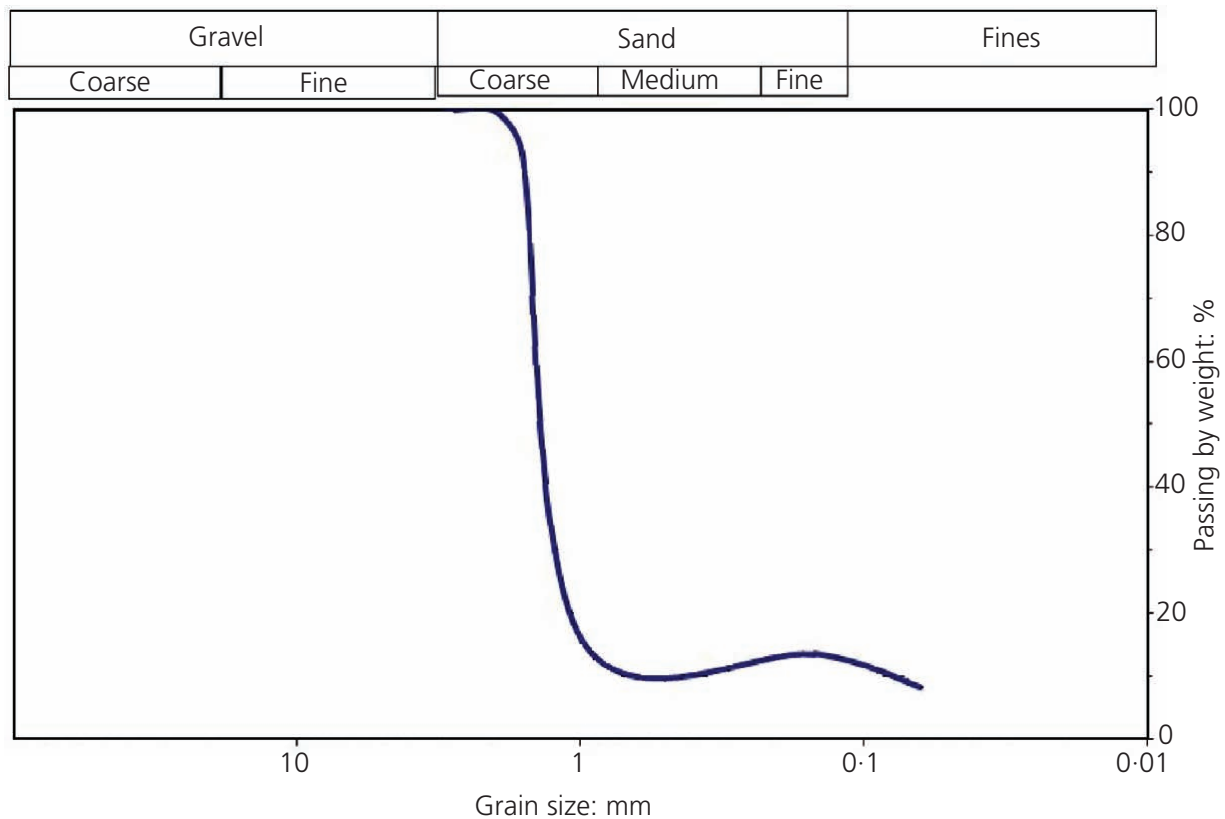

Figure 7. Grain size distribution based on a sieve analysis for wet sample 
Table 3. TPH analysis of the oil-contaminated samples

\begin{tabular}{|c|c|c|c|c|}
\hline Sample & & Weight of sample: $\mathbf{g}$ & Weight of crude oil sediment: $\mathbf{g}$ & Concentration of oil residue (TPH): $\mathrm{mg} / \mathrm{kg}$ \\
\hline \multirow[t]{5}{*}{ Oil lake 105} & Trial 1 & 1.02 & 0.33 & 320000 \\
\hline & Trial 2 & 1.01 & 0.35 & 350000 \\
\hline & Trial 3 & 1.00 & 0.31 & 310000 \\
\hline & Trial 4 & 1.09 & $0 \cdot 35$ & 321000 \\
\hline & Trial 5 & $1 \cdot 22$ & $0 \cdot 39$ & 320000 \\
\hline \multirow[t]{5}{*}{ Oil lake 106} & Trial 1 & $1 \cdot 10$ & $0 \cdot 35$ & 320000 \\
\hline & Trial 2 & $1 \cdot 10$ & $0 \cdot 37$ & 340000 \\
\hline & Trial 3 & 0.09 & $0 \cdot 30$ & 330000 \\
\hline & Trial 4 & 1.05 & $0 \cdot 32$ & 300000 \\
\hline & Trial 5 & $1 \cdot 12$ & $0 \cdot 35$ & 322000 \\
\hline \multirow[t]{5}{*}{ Oil lake 107} & Trial 1 & $1 \cdot 10$ & $0 \cdot 37$ & 340000 \\
\hline & Trial 2 & $1 \cdot 14$ & 0.39 & 340000 \\
\hline & Trial 3 & $1 \cdot 10$ & 0.36 & 330000 \\
\hline & Trial 4 & $1 \cdot 16$ & 0.40 & 345000 \\
\hline & Trial 5 & $1 \cdot 18$ & $0 \cdot 38$ & 320000 \\
\hline
\end{tabular}

(2008), soils contaminated with crude oil represent a significant risk to the environment and human health. The weathering process brings about a higher binding strength of crude oil to soil. As such, it is obvious that weathered contaminated soils are more difficult to remediate in comparison with soils that have been recently contaminated. Crude oils have low water solubility and high adsorption onto the soil matrix and present a very low rate of mass transfer for biodegradation (Banat et al., 2000). In order to choose the most appropriate method, an exhaustive list of each of the remediation options has been reviewed. As exhibited in Figure 5, a matrix was formulated to show the interrelationships, while the weights and alternatives were ascertained and assessed against the requirements. Hence, weighted alternatives have been formulated. The process began by converting the set symbols to their corresponding values. Each value was later multiplied by the weight of its characteristic. This process was repeatedly carried out for all the characteristics, and the total sum was derived at the final stage. As seen in Figure 5, the relative weight for bi-piles was $7 \%$. There is a similar weight score recorded among land farming, windrow, phytoremediation and vermiremediation; the outcome shows that the score of relative weight was $8 \%$. Likewise, the results also exhibited that the score of the relative weights for electroremediation and solidification/stabilisation was $9 \%$, while the scores of relative weight for bioventing, thermal adsorption and soil washing were 12,14 and $18 \%$, respectively. The major change in the soil materials takes place during the thermal treatment stage. Usually, high-temperature procedures damage the organic compounds and clay minerals, hydroxides are transformed into oxides and main minerals are converted to fine soil. In addition, compared with other thermal and bioremediation technologies, the soil washing method has some major benefits. From the results, soil washing appears to be the best method in view of its total score, while thermal adsorption cannot be employed based on UN requirements. A large number of remediation methods have been designed in an attempt to reduce the effects of petroleum pollution on the environment. Due to the large differences in the physical, chemical and biological characteristics of the contaminants, remediation can be difficult.
For this study, nine remediation technologies were considered to assess their suitability to treat soil contaminated with hydrocarbons. These technologies were land farming, windrow, phytoremediation, vermiremediation, bioventing, soil washing, biopiles, electroremediation and solidification/stabilisation. Based on the evidence collected, each soil remediation technique was categorised (see Table 4) either as less suitable, suitable or more suitable for the treatment of sandy soil contaminated with hydrocarbons. Different criteria were considered for selecting appropriate methods such as soil constraints, implementation in surface soil, need for further treatment, removal of compounds, timescale for clean-up and cost. Bioremediation is a degradative or transformative approach aiming to stimulate microorganisms to grow and live on contaminants as their source of food and energy by introducing an environment conducive for the growth of the microorganisms. Nonetheless, it is time consuming and it is hard to confirm whether the contaminants have been entirely eliminated. In the biological remediation of high-molecularweight PAHs, which are less biodegradable, contaminants could be left behind. While a greater concentration of hydrocarbons can become toxic or act as an inhibitor to the microorganisms, the presence of an exceptionally low concentration of hydrocarbons may prove insufficient for the sustenance of microbial activities. PAHs with higher molecular structures are known to be carcinogens. In general, bioremediation is not suitable to be used as treatment of inorganic contaminants. Soil contaminated with oil is particularly challenging to treat by bioremediation because excess oil produces droplets or films on soil particles, which become a major obstacle to microbial degradation (Urum et al., 2004). Each of the remedial methods was also assessed for its capability to treat sandy soil. In employing physical treatments, the physical properties of the contaminants or the contaminated medium are utilised to destroy, segregate or accommodate the contamination. One of the physical treatments is soil washing; it is commonly regarded as an effective and affordable method and requires a shorter completion time (when compared against biological treatment). This technique seems to be one of the best techniques for handling a broader spectrum of organic 


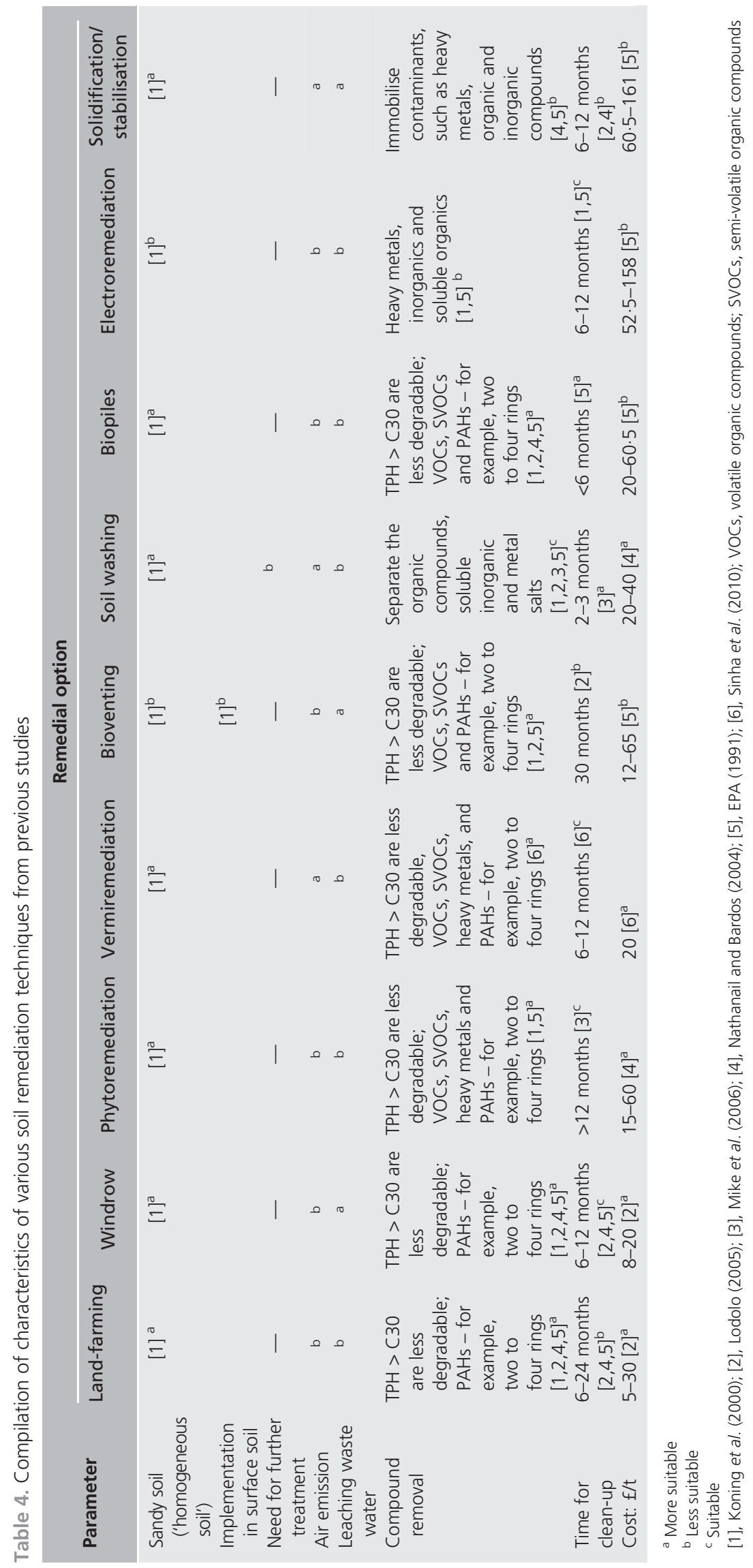


An assessment of remediation strategies

for Kuwaiti oil lakes

Almutairi contaminants, in particular petroleum hydrocarbons. It has been acknowledged that soil washing is capable of treating coarse material better than soils with higher silt contents (Mulligan et al., 2001). This is because coarse materials are highly porous to liquids, which allows them to bind a lower amount of contaminants due to their smaller particle surface areas per unit volume (Wang and Keller, 2008). Therefore, in order to reduce substantially the amount of the most contaminated soils, it is recommended to separate the fine soil (clay and silt) from the coarse soil (sand and gravel) before or during the processes (Anderson et al., 1999). The employment of surfactants has been proven to be a viable method in the extraction of more hydrophobic compounds from soils - for instance, organic contaminants (Mulligan et al., 2001). With the presence of electrolytes, the critical micelle concentration (CMC) of anionic surfactants is significantly reduced, resulting in the increase of aggregation number and size of micelles, as asserted by Bai et al. (1998). In the design of the soil washing technique, it is vital that the interaction between the surfactant and salt and its resultant effect on surfactant performance is thoroughly understood. This will be considerably central as non-ionic surfactants are not affected by the presence of electrolyte in the solution. This is exceptionally interesting in the field application of soil washing as the Kuwaiti oil-contaminated soil is likely to contain electrolytes - for example, calcium $\left(\mathrm{Ca}^{2+}\right)$, magnesium $\left(\mathrm{Mg}^{2+}\right)$, sodium $\left(\mathrm{Na}^{+}\right)$ and potassium $\left(\mathrm{K}^{+}\right)$ions - which perhaps were introduced when seawater was used during firefighting activities. The results obtained in this study showed that soil washing appeared to be the most appropriate option for the treatment of sandy soil contaminated with oil. Some of its benefits are cost-effectiveness, scalability and an exceptional ability to remove oil from contaminated soil within a short time. It has less profound sideeffects, but the removal of contaminants can be controlled by enhancing the washing parameters. Based on Table 4, the selected technique requires about 1 year to achieve the remediation target and is the cheapest of the available approaches, with the maximum treatment cost of $£ 40 / t$ of soil. This method can be employed on its own or performed in series. By using ex situ techniques for soil washing, the coarser material can be used for construction works such as subgrade fill or backfill, landfill capping or concrete production.

\section{Conclusion}

The scenario in Kuwait is somehow exceptional as the contamination is primarily caused by crude oil, which has been weathered under a harsh desert environment for more than 24 years. The exposure to the environment has caused most of the volatile substances within the crude oil to evaporate into the atmosphere, with heavy compounds left as residue. Due to the complex nature of contaminated soil and a cocktail of various types of pollutants, different types of remediation are required to deal with the wide range of contaminants, and limited success has been reported for remediation of contaminated soil. The higher levels and wider ranges of TPH have shown interesting patterns in Kuwait oil lakes. Most importantly, these contaminated sites have not yet been restored, and therefore pose continual potential hazards to the environment and human health. Therefore, it is important to estimate characteristics of the contaminated soil, to perform tests to simulate the field conditions and to provide categorisation of the sample, without which it will be impossible for the planning of land use and options of remediation to be taken into account. Based on the literature, bioremediation is unlikely to be successful given the high concentration of TPH and high concentration of the salts in Kuwaiti contaminated soil. Furthermore, thermal treatment is not allowed based on UN requirements. Although selecting a remediation scheme challenges decision makers to compare and select appropriate soil remediation techniques, this research was able to choose soil washing for remediation of Kuwaiti oil-contaminated sand based on a decisionmaking tool known as the HOQ system, which complies with the set of UN requirements.

\section{Acknowledgements}

The author is grateful to the staff of KOC and the Kuwait Institute of Scientific Research, particularly for the sampling task.

\section{REFERENCES}

Al-Ajmi DF, Misak FI, Khalaf M, Al-Sudairawi and Al-Dousari AM (1994) Damage Assessment of the Desert and Coastal Environment of Kuwait by Remote Sensing. Kuwait Institute for Scientific Research, Safat, Kuwait, Report KISR 4405.

Al-Awadhi N, Al-Daher R, Balba M, Chino H and Tsuji H (1998) Bioremediation of oil-contaminated desert soil: the Kuwait experience. Environment International 24(1/2): 163-173.

Al-Naseem A and Al-Duwaisan D (2011) Characterization of oil contaminated soil. In Proceedings of the 2nd International Conference on Environmental Science and Technology. IPCBEE IACSIT Press, Singapore, vol. 6, pp. 439-442.

Anderson R, Rasor E and Van Ryn F (1999) Particle size separation via soil washing to obtain volume reduction. Journal of Hazardous Materials 66(1-2): 89-98.

Bai G, Brusseau ML and Miller RM (1998) Influence of cation type, ionic strength and $\mathrm{pH}$ on solubilization and mobilization of residual hydrocarbon by a biosurfactant. Journal of Contaminant Hydrology 30(3-4): 265-279.

Banat IM, Makkar RS and Cameotra SS (2000) Potential commercial applications of microbial surfactants. Journal of Applied Microbiology 53(5): 495-508.

Bodó B and Jones C (2013) Introduction to Soil Mechanics. WileyBlackwell, Hoboken, NJ, USA.

BSI (1990a) BS EN 1377-5:1990: Method of test for soil for civil engineering purposes. Compressibility, permeability and durability tests. BSI, London, UK.

BSI (1990b) BS EN 1377-2:1990: Methods of test for soils for civil engineering purposes. Classification tests. BSI, London, UK.

BSI (2005) BS ISO 10390:2005: Soil quality. Determination of pH. BSI, London, UK.

BSI (2011) BS EN 13038:2011: Soil improvers and growing media. Determination of electrical conductivity. BSI, London, UK.

Ejbarah N, Al-Jarallah R and Al-Duwaisan D (2011) House of Quality application in soil remediation. Proceedings of the 2 nd International Conference on Environmental Science and Technology. IPCBEE IACSIT Press, Singapore, vol. 6, pp. 423-427.

El-Baz F, Abuelgasim A, Koch M et al. (1994) Detection by satellite images of environmental change due to the Gulf War. In The Gulf War and the Environment (El-Baz F and Makharita RM (eds)). Gordon and Breach Science, Lausanne, Switzerland, pp. 1-24. 
An assessment of remediation strategies

for Kuwaiti oil lakes

Almutairi
EPA (US Environmental Protection Agency) (1991) Guide for Conducting Treatability Studies under CERCLA: Soil Washing. EPA, Washington, DC, USA, Interim Guidance EPA/540/2-91/020A.

Hauser JR and Clausing DP (1988) The House of Quality. Harvard Business Review: pp. 63-73. See https://hbr.org/1988/05/the-house-ofquality (accessed 30/05/2017).

Koning M, Hupe K and Stegmann R (2000) Thermal processes, scrubbing/ extraction, bioremediation and disposal. In Biotechnology: Environmental Processes II, 2nd edn. (Rehm HJ and Reed G (eds)). Wiley-VCH, Weinheim, Germany, vol. 11b, pp. 306-317.

Kwarteng AY (1998) Multitemporal remote sensing data analysis of Kuwait's oil lakes. Environment International 24(1/2): 121-137.

Kwarteng AY (1999) Remote sensing assessment of oil lakes and oil polluted surfaces at the Greater Burgan oil field, Kuwait. International Journal of Applied Earth Observation and Geo-information 1(1): 36-47.

KOC (Kuwait Oil Company) (2015) Oil Lake. KOC, Ahmadi, Kuwait. See https:/www.kockw.com/sites/EN/Pages/We\%20Care/OilLakes.aspx (accessed 17/10/2015).

Li X, Li P, Lin X et al. (2008) Biodegradation of aged polycyclic aromatic hydrocarbons (PAHs) by microbial consortia in soil and slurry phases. Journal of Hazardous Materials 150(1): 21-26, https://doi.org/10. 1016/j.jhazmat.2007.04.040.

Li X, Dua Y, Wua G et al. (2012) Solvent extraction for heavy crude oil removal from contaminated soils. Chemosphere 88(2): 245-249, https://doi.org/10.1016/j.chemosphere.2012.03.021.

Lodolo A (2005) Remediation technologies and decision support tools for their assessment and selection. Proceedings of the $3 \mathrm{rd}$ Workshop on Integrated Sediment and Soil Assessment, Brno, Czech Republic.

Mike P, Pruijn M and Bovendeur J (2006) The application of soil washing to the remediation of contaminated soils. Land Contamination \& Reclamation 14(3): 713-726.

Mulligan CN, Yong RN and Gibbs BF (2001) Surfactant-enhanced remediation of contaminated soil: a review. Journal of Engineering Geology 60(1-4): 371-380.
Nathanail CP and Bardos RP (2004) Reclamation of Contaminated Land. Wiley, Hoboken, NJ, USA.

Omar S, Grealish G and Roy W (2006) Types and extent of soil contamination in Greater Al-Burgan oil field. Kuwait Journal of Science and Engineering 33(2): 89-99.

PEC (Petroleum Energy Center) (1999) Survey of Technology for Remediation of Oil-Contaminated Soil in Kuwait. Survey 8, Tokyo, Japan. See http://www.pecj.or.jp/japanese/report/reserch/report-pdf/ H11 1999/99surv8-e.pdf (accessed 30/05/2017).

Petroleum Economist (1992) The oil ${ }^{\mathbb{R}}$ res story. International Energy Journal 59(4): 21-28.

Riser-Roberts E (1998) Remediation of Petroleum Contaminated Soils: Biological, Physical, and Chemical Processes. Lewis Publishers, Boca Raton, FL, USA, pp. 6-7.

Russel RS and Taylor BW (2006) Products and services. In Operations Management: Quality and Competitiveness in a Global Environment, 5th edn, Chapter 5. Wiley, Hoboken, NJ, USA, pp. 178-190.

Sinha RK, Herat S, Valani D and Chauhan K (2010) Earthworms - the environmental engineers: review of vermiculture technologies for environmental management \& resource development. International Journal of Global Environmental Issues 10(3-4): 265-292, http://dx. doi.org/10.1504/IJGENVI.2010.037271.

Sui $X$ and Ji GD (2010) Impact of ultrasonic power density on elution of super heavy oil and its biomarkers from aging soils using Triton X100 micellar solution. Journal of Hazardous Materials 176(1-3): 473-480.

UNCC (UN Compensation Commission) (2004) Claim of the State of Kuwait Claim No 5000454. UNCC, Geneva, Switzerland. Report No. S/AC26/2004/17.

Urum K, Pekdemir T and Çopur M (2004) Surfactants treatment of crude oil contaminated soils. Journal of Colloid and Interface Science 276(2): 456-464.

Wang P and Keller A (2008) Particle-size dependent sorption and desorption of pesticides within water-soil-nonionic surfactant system. Environmental Science \& Technology 42: 3381-3387.

\section{How can you contribute?}

To discuss this paper, please submit up to 500 words to the editor at journals@ice.org.uk. Your contribution will be forwarded to the author(s) for a reply and, if considered appropriate by the editorial board, it will be published as a discussion in a future issue of the journal. 